\title{
Autosomal dominant focal dystonia, DYT25 type
}

INSERM

\section{Source}

INSERM. (1999). Orphanet: an online rare disease and orphan drug data base. Autosomal dominant focal dystonia, DYT25 type. ORPHA:329466

Autosomal dominant focal dystonia, DTY25 is a form of focal dystonia (see this term), characterized by cervical, laryngeal and hand-forearm dystonia (see these terms). 